\title{
UTILIZATION OF POLYPROPYLENE IN BITUMINOUS CONCRETE
}

\author{
EZEMENIKE CHUKWUKA ${ }^{1 *}$, OLADELE ISIAKA ${ }^{2}$, ADERINLEWO \\ OLUFIKAYO $^{1}$, OYEDEPO OLUGBENGA ${ }^{1}$ \\ ${ }^{I}$ Department of Civil Engineering, Federal University of Technology, P.M.B, 704, Akure, \\ Ondo State, Nigeria \\ ${ }^{2}$ Department of Metallurgical Materials Engineering, Federal University of Technology, \\ P.M.B, 704, Akure, Ondo State, Nigeria
}

\begin{abstract}
The utilization of polypropylene in form of waste plastic to produce bituminous concrete for pavement construction was studied. The aggregates, bitumen and polypropylene were characterized. Bitumen was partially replaced with polypropylene at 2 , 4,6 and $8 \%$ by weight to produce asphalt concrete, thereafter, Marshal Stability and flow test was carried out on asphalt concrete. From the result, Marshal Stability values of 8.77, $9.18,9.5$ and $11.51 \mathrm{KN}$ while flow values of $3.5,3.2,3.1$ and $2.8 \mathrm{~mm}$ were respectively obtained. This study suggests that the polypropylene could enhance the performance of asphalt concrete and decrease the cost of road construction.
\end{abstract}

Keywords: polypropylene, waste plastics, bitumen, aggregate, asphalt concrete, stability, flow

\section{INTRODUCTION}

There is increase in the manufacturing and utilization of plastic products. This is compounded by population density. The resultant effect is the poor management of disposal plastic waste which plagues some developing countries. Nigeria is among developing countries that has witnessed enormous challenges in plastic and other polymer-related waste management. Plastic waste fills about $90 \%$ of World River which are major causes of 20$30 \%$ death of aquatic animal [1]. The quantity of plastic generated last year is more than the figures produced in earlier years. Internationally, plastics request rose from 320 million tons in 2015 to more than 330 million tons in 2016 alone [2]. This suggests that waste plastic is multiplying its harm on all-natural frameworks and life [3].

Plastics have perpetually influenced man's everyday living and their proceeded usage and production particularly in most low-income countries are presently in trouble, since they will be unable cope with the high-level methods of plastic waste management [4]. Additionally, the characteristics of plastics, for example, lightweight and toughness that make them so exceptional have resulted into a disposal issue. When used plastic items are discarded into the surrounding, they do not decompose while in the environment because of the way that they are tough; while those tossed into water bodies keep drifting at a surface level since they are of low density [5]. Hence, the harm these wastes are getting to life and the environment is raising subsequently causing serious atmospheric hazard, for example, soil, air and water contamination.

\footnotetext{
${ }^{*}$ Corresponding author, email: ezestan2013@gmail.com

(C) 2021 Alma Mater Publishing House
} 
On the other hand, plastic waste can be reused and utilized as either additive or re-enforcement in producing composite material in road construction project because its high molecular mass. Utilizing plastic waste in pavement construction is a new invention and no pavement have been constructed totally from plastic waste, nevertheless, a research done by [6] implied that recycled waste plastic can serve as both binder modifier and aggregate replacement [7-9] concluded in their research that plastic has ability for use in asphaltic road as its inclusion in a little portion of $5-10 \%$ by weight of bitumen aids in enhancing desirable properties of asphalt mixtures such as strength, stability and fatigue life of pavement and it also help to increase pavement performances and longevity.

The use of plastic waste in asphalt concrete mixture improves the resistance to deformation, water-induced damage, and durability. Indirectly, it assists in accident-reduction and satisfaction of road users [10-15]. Studies on recycled polyethylene terephthalate (PET) plastic bottle waste in bituminous asphalt concrete conclude that plastic waste utilized in road construction can provide road service life. [16] Investigations have been carried out into the effect of adding plastic to bituminous mixture performance with $0 \%, 0.2 \%, 0.5 \%$ and $1 \%$ of plastic waste. The results indicated that adding $0.2 \%$ plastic waste to a hot-mix of asphalt improves the asphalt mixture's performance and [17] uses $7.0 \%$ optimum bitumen content with (2.5-15) \% at $2.5 \%$ interval of waste polythene. In their study on effect of polythene-modified bitumen properties of hot-mix asphalt, their result suggests that polythene is a modifier that could provide better engineering properties and aid better ways of managing wastes.

In another study carried out by [18] on utilization of waste-based geopolymer in asphalt pavement construction and modification, they studied the modification of bitumen with two geopolymers; namely geopolymer modified asphalt mixture (GMAM) and geopolymer modified asphalt (GMA). They concluded that using geopolymers in asphalt concrete pavement has economic, environment and sustainability benefit. Moreover, [19] carried a study on utilization of industrial waste product in asphalt concrete mixture for road construction. He used crushed ceramic tile (CCT) and aluminum slag (AS) at $10 \%$ to $50 \%$ by weight at $10 \%$ interval. The results showed that their percentages were suitable for light, medium and heavy traffic when compared with Asphalt institute for marshal design criteria.

Environment-friendly and sustainable development have been the major interest in many industrial sectors especially construction industry. The natural resource depletion and degradation of environment arising from the production of constituent materials is a major interest to highway researchers. lately the materials use in road construction are in great demand, however there is a need to explore other available non-conventional materials such as industrial waste from plastic industry to wholly or partially replace the conventional materials. This research work is carried out utilized polypropylene in form of waste plastic in asphalt concrete.

\section{MATERIALS AND METHOD}

\subsection{Materials}

Aggregate, polypropylene and bitumen were utilized for this study. Aggregate was procured from RCC and JCC quarry, Oba-Ile, Ondo state, Nigeria. The 60/70 penetration grade Bitumen was obtained from K.K. Hassan Construction Company in Akure, Nigeria while polypropylene in form of waste plastic chairs were collected in churches, mosques and resultants within Akure metropolis.

\subsubsection{Equipment used}

Equipment used include: set of sieves and sieve shaker, oven, weighing balance, grinding machine, moisture content apparatus, aggregate impact testing machine, aggregate crushing testing machine, specific gravity bottles, bitumen penetrometer, Softening point apparatus (ring and ball method), Cleveland open cup flash and fire point tester, Dynamic viscometer, ductilimeter, flakiness and elongation apparatus, water in bitumen apparatus (Dean and stark method) and Marshall Stability test Apparatus.

\subsection{Methods}

The methods employed are discussed in the preceding subsection.

\subsubsection{Processing of waste plastic chairs, aggregate, bitumen and their characterization}

The crushed stone was sieved to obtain size range of $150 \mu \mathrm{mm}$ to $10 \mathrm{~mm}$. Sieve analysis was performed to guarantee aggregate for stone dust, fineness and coarseness. Other tests such as specific gravity, moisture 
content, aggregate crushing, aggregate impact, flakiness and elongation test were carried out on aggregate in other to characterize it. Softening point, penetration, flash and fire point, viscosity, ductility, and water-inbitumen test was carried on bitumen to determine physical properties of bitumen. The polypropylene in form of waste plastic was ground to obtain a polypropylene powder with a particle size passing $0.015 \mu \mathrm{mm}$ and this was also carried out to guarantee polypropylene used to replace conventional bitumen at proportion of $2 \%, 4 \%, 6 \%$, and $8 \%$.

\subsubsection{Marshall bituminous mix design (ASTM D 6927-06) and composites development}

Aggregates of about $1200 \mathrm{~g}$ comprising distinct aggregate fractions with sizes of $8.00,5.00$ and $2.36 \mathrm{~mm}$ and, filler (stone dust) of $4.76 \mu \mathrm{m}$ were pre-heated within the range of $160-178{ }^{\circ} \mathrm{C}$. The selected bitumen content of $5 \%$ was melted to $150^{\circ} \mathrm{C}$. The aggregates and bitumen were mixed together inside the steel bowl. The mix was completely blended at mixing temperature of about $185^{\circ} \mathrm{C}$. The mixture was compacted in fore-heat marshal mould by applying 50 blows on each face of the sample. Specimen was reversed and the same numbers of blows were applied on the opposite side. 15 samples of asphalt concrete mixture were prepared with powdered polypropylene to test the effect of adding to the mixture. The samples were prepared by adding five different proportions $(2,4,6$, and $8 \%)$ of polypropylene as a replacement for bitumen in asphalt concrete. The marshal stability and flow were carried out on the samples while Void in mineral aggregate (VMA), Air void (AV), bulk density (BD) and Void filled with bitumen (VFB) was determined.

\section{RESULTS AND DISCUSSION}

\subsection{Sieve analysis}

Figure 1 gives the result of sieve analysis for the aggregates. From Figure 1, it can be observed that the selected aggregate falls within the standard specified envelope for hot asphalt mix design. The particle distribution chart is shown in Figure 1. The results of the sieve analysis (BS 812-103, 1990) of the aggregate shown below indicates that the materials are well graded, their sizes vary from coarse to fine to provide interlocking between them. The results fall within the Federal Government of Nigeria General Specification for road and bridges [20] specified limits.

PARTICLE SIZE DISTRIBUTION CURVE

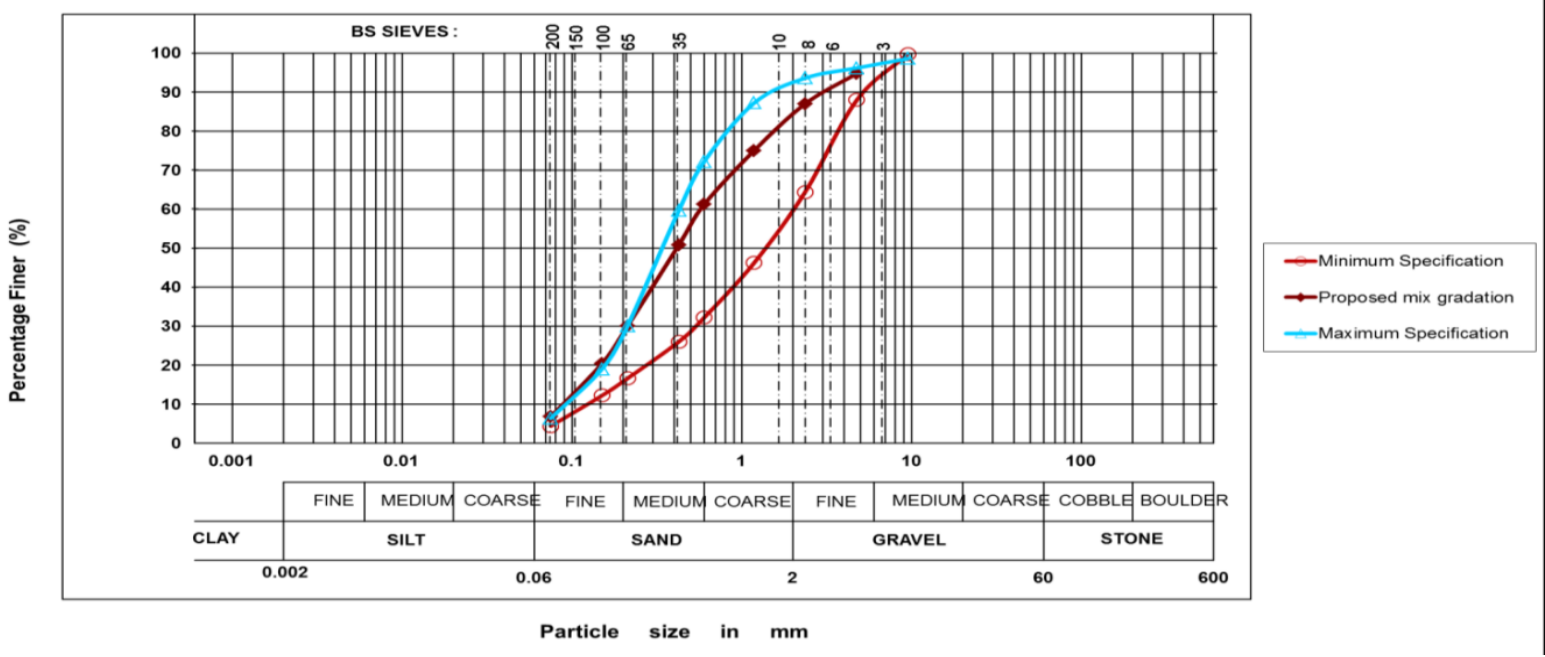

Fig. 1. Particle size distribution curve of aggregate.

Table 1 presents the values obtained for the moisture content, aggregate impact (AIV), aggregate crushing (ACV), specific gravity, flashiness and elongation as; $0.65 \%, 22.20 \%, 30.18 \%, 3.0 \mathrm{~g}$ and 20.64 , respectively. From the results, it was observed that the aggregates conformed to relevant code recommendations which mean that the aggregates are tough, dense and can stand the test of both serviceability and durability requirement. Thus, they are suitable for the production of wearing course of asphalt concrete according to British standard and American standard for testing materials. 
Table 2 presents the results of the penetration, softening point, flash point, fire point, ductility, viscosity and water-in-bitumen as; $62 \mathrm{~mm}, 46^{\circ} \mathrm{C}, 207^{\circ} \mathrm{C}, 252^{\circ} \mathrm{C}, 148 \mathrm{~cm}, 129.4 \mathrm{sec}$ and $3.4 \%$, respectively. All these values conformed to American standard for testing material specified range.

Table 1. Physical properties of aggregate.

\begin{tabular}{|l|c|c|c|}
\hline \multicolumn{1}{|c|}{ Test Conducted } & Code Used & Code Limit & Test result \\
\hline Moisture Content (\%) & (BS 812-109:1990) & $\max 5 \%$ & $0.65 \%$ \\
\hline Aggregate Impact value (\%) & (BS 812-112:1990) & $20-30 \%$ & $22.20 \%$ \\
\hline Specific gravity & (ASTMC 127-12) & $2.5-3.0 \mathrm{~g}$ & $3.0 \mathrm{~g}$ \\
\hline Aggregate Crushing value (\%) & (ASTMC 131/C131 & $27-35 \%$ & $30.18 \%$ \\
\hline Flakiness and Elongation Index test (\%) & (BS 812:105:1:1985) & $\max 30$ & $20.64 \%$ \\
\hline
\end{tabular}

Table 2. Physical properties of bitumen.

\begin{tabular}{|l|c|c|c|}
\hline \multicolumn{1}{|c|}{ Test Conducted } & Code Used & Code Limit & Test result \\
\hline Penetration, $\mathrm{mm}$ & (ASTM D5-95 & $60-70$ & $62 \mathrm{~mm}$ \\
\hline Softening Point, ${ }^{\circ} \mathrm{C}$ & ASTM D36-76 & $\min 45$ & $46{ }^{\circ} \mathrm{C}$ \\
\hline Flash point, ${ }^{\circ} \mathrm{C}$ & ASTM D92-90 & $\min 200$ & $207^{\circ} \mathrm{C}$ \\
\hline Fire Point, ${ }^{\circ} \mathrm{C}$ & ASTM D92-90 & $\min 240$ & $252^{\circ} \mathrm{C}$ \\
\hline Ductility, cm & ASTM D92-90 & $\min 75$ & $148 \mathrm{~cm}$ \\
Viscosity, sec & ASTM D92-90 & - & $129.4 \mathrm{sec}$ \\
Water-in-Bitumen & ASTM D95 & $\max 5 \%$ & $3.4 \%$ \\
\hline
\end{tabular}

\subsection{The bituminous marshal results}

Table 3 shown the bituminous marshal results utilizing polypropylene as partial replacement to bitumen in asphalt concrete while the summary of the criteria for bituminous marshal mix design method utilized is indicated in Table 4.

Table 3. Waste plastic modified with asphalt concrete.

\begin{tabular}{|c|c|c|c|c|c|c|c|}
\hline S/NO & $\begin{array}{c}\text { Percentage } \\
(\mathbf{\%})\end{array}$ & $\begin{array}{c}\text { Bulk density } \\
\left(\mathbf{g} / \mathbf{m}^{\mathbf{3}}\right)\end{array}$ & $\begin{array}{c}\text { air void } \\
(\mathbf{\%})\end{array}$ & $\begin{array}{c}\text { VMA } \\
(\boldsymbol{\%})\end{array}$ & $\begin{array}{c}\text { VFA } \\
(\mathbf{\%})\end{array}$ & $\begin{array}{c}\text { Stability } \\
(\mathbf{K N})\end{array}$ & $\begin{array}{c}\text { Flow } \\
(\mathbf{m m})\end{array}$ \\
\hline 1 & 0 & 2.467 & 4.18 & 21.70 & 80.73 & 7.45 & 3.8 \\
\hline 2 & 2 & 2.458 & 4.54 & 21.99 & 79.35 & 8.77 & 3.5 \\
\hline 3 & 4 & 2.454 & 4.69 & 22.12 & 78.78 & 9.18 & 3.2 \\
\hline 4 & 6 & 2.437 & 5.36 & 22.66 & 76.34 & 9.59 & 3.1 \\
\hline 5 & 8 & 2.427 & 5.76 & 22.99 & 74.94 & 11.51 & 2.8 \\
\hline
\end{tabular}

Table 4. Typical bituminous Marshall design criteria.

\begin{tabular}{|l|c|c|c|c|c|c|}
\hline \multicolumn{1}{|c|}{ Mix Specification } & \multicolumn{2}{|c|}{$\begin{array}{c}\text { Heavy traffic (greater } \\
\text { than 10 }\end{array}$} & \multicolumn{2}{c|}{$\begin{array}{c}\text { Light traffic (less } \\
\text { than 104 ESAL) }\end{array}$} & \multicolumn{2}{c|}{$\begin{array}{c}\text { Medium Traffic }\left(\mathbf{1 0}^{4}-\mathbf{1 0}^{\mathbf{6}}\right. \\
\text { ESAL) }\end{array}$} \\
\hline & Min & Max & Min & Max & Min & Max \\
\hline Stability (minimum) & $6672 \mathrm{~N}$ & - & $2224 \mathrm{~N}$ & - & 3336 & - \\
\hline Flow (0.25mm) & 8 & 16 & 8 & 20 & 18 & - \\
\hline Air voids (\%) & 3 & 5 & 3 & 5 & 3 & 5 \\
\hline $\begin{array}{l}\text { Compaction (50 blows } \\
\text { each side of specimen) }\end{array}$ & 35 & - & 50 & - & 75 & - \\
\hline
\end{tabular}

Note: ESAL is the Equivalent Single Axle Load; Source: Asphalt Institute [21]

\subsubsection{Bulk density}

In Figure 2, the bulk density showed a constant decrease as polypropylene increase. It was found a constant decrease from $2 \%$ to $8 \%$ polypropylene. This may be as a result of the lower specific gravity of polypropylene which is lower than conventional bitumen. This observation agreed with [22].

\subsubsection{Marshal stability}

The variation of the stability values is shown in Figure 3. It was noted that there was a constant increase from $2 \%$ to $8 \%$ polypropylene content. This may be attributed to higher cohesion of binder and internal friction which enhance the performance of asphalt concrete and its strength [23]. The result also showed that the percentage of 
$0,2,4,6$ and $8 \%$ falls within minimum specified value for light traffic, medium traffic and heavy traffic. It can be deduced from result that marshal stability values satisfied the specification given by Asphalt Institute [21].

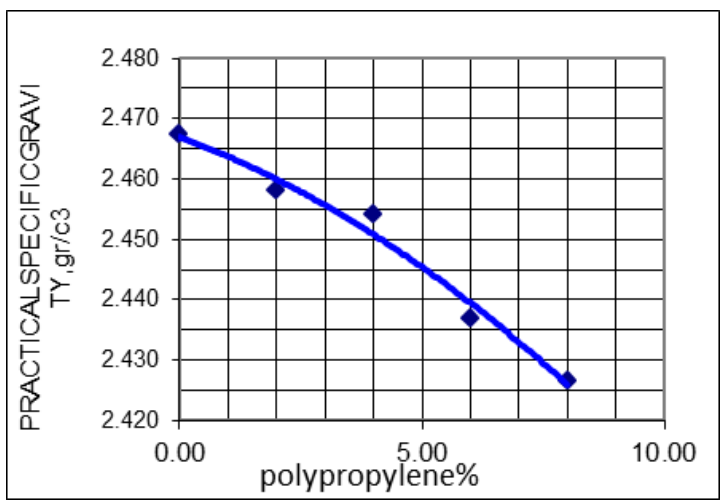

Fig. 2. Bulk density.

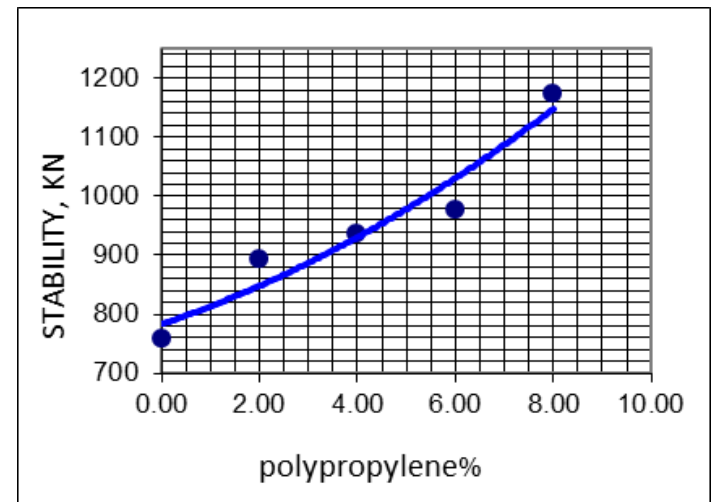

Fig. 3. Stability.

\subsubsection{Flow}

The variation of flow is as shown in Figure 4, it was found a constant decrease from $2 \%$ to $8 \%$ polypropylene. This may be attributed to the reduction in viscosity of the binder with increasing polypropylene content as observed during the experiment. This agrees with the result of [24] who noted that reduction in flow suggests that polymer content has increased effect on the internal friction of the mix. The flow values did not meet up with Asphalt institutes specification but conformed to Nigeria general specification for road and bridge [20] which stated that maximum of $4 \mathrm{~mm}$ to minimum of $2 \mathrm{~mm}$ is the acceptable range for wearing course in production of asphalt concrete.

\subsubsection{Air void (AV)}

Figure 5 shows the result of the air void. So, it can be observed that the air void of modified asphalt mixture increases gradually as the polypropylene content increased till it reached the highest AV\% value at $8 \%$ waste plastic. This is because the modifier fills the voids in the asphaltic mixture. This result corroborates with the findings of [23]. The air void result conformed to the asphalt specification for heavy, medium and light traffic.

\subsubsection{Void in mineral aggregate (VMA)}

The variation of Void in mineral aggregate is as shown in Figure 6, there was a constant increase from $0 \%$ to $8 \%$, the results comply with the findings of [24] and disagreed with the observation of [23].

\subsubsection{Void filled with bitumen (VFB)}

The variation of Void filled with Bitumen is as shown in Figure 7, there was decrease from $0 \%$ to $8 \%$. The results comply with the findings of [23] and [24].

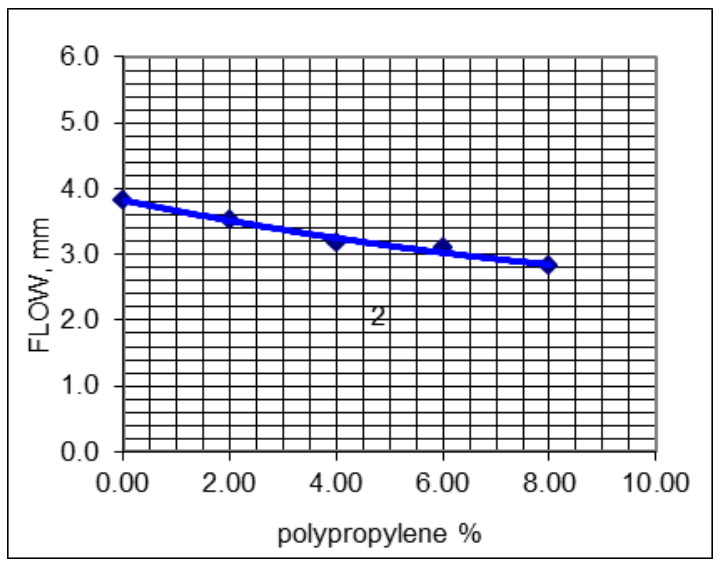

Fig. 4. Flow.

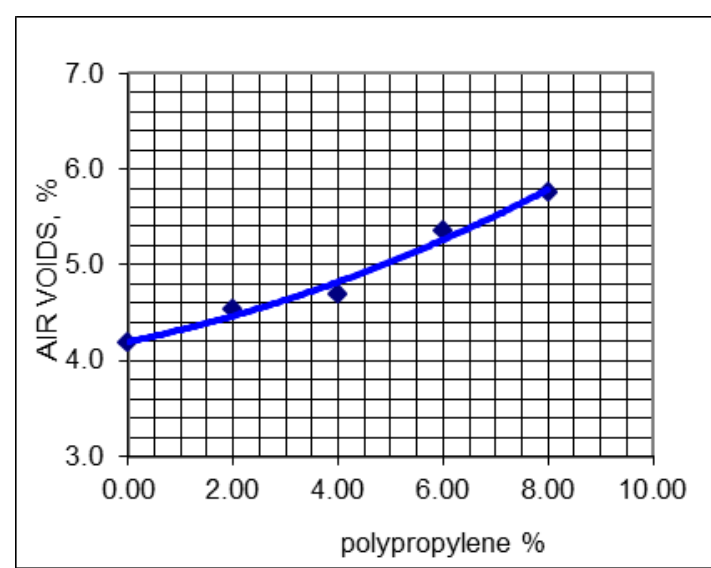

Fig. 5. Air void. 


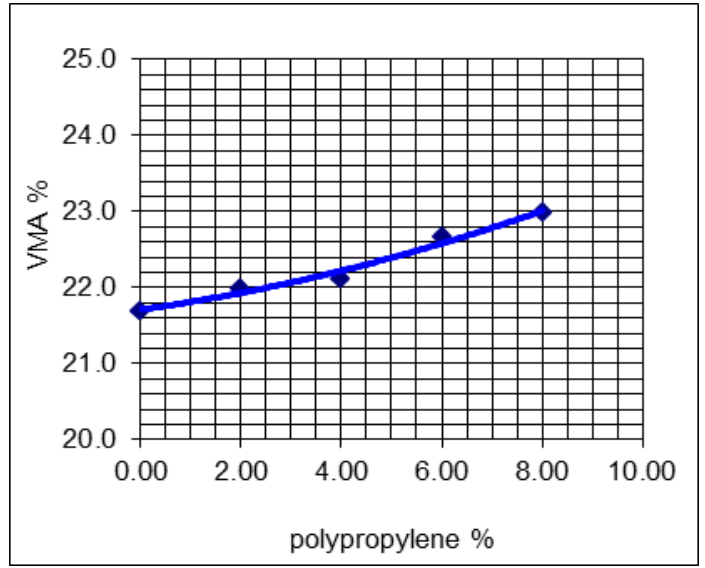

Fig. 6. Void in mineral aggregate.

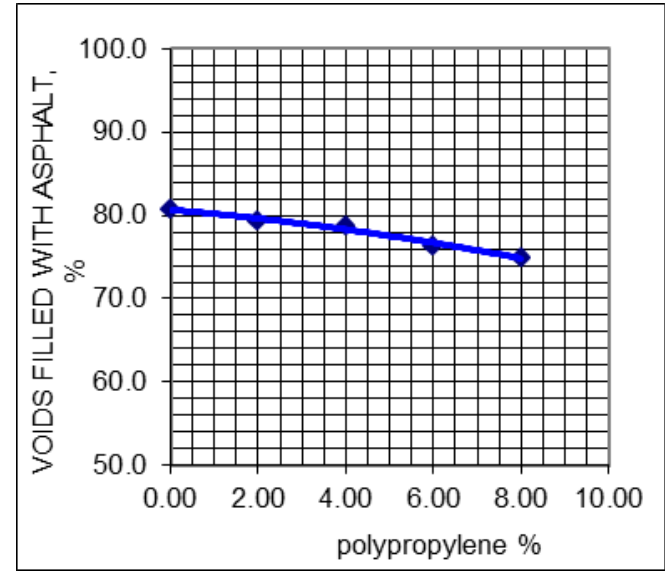

Fig. 7. Void filled with bitumen.

\section{CONCLUSIONS}

The following findings were performed in the present study:

- The marshal stability value of $7.45 \mathrm{KN}, 8.77 \mathrm{KN}, 9.18 \mathrm{KN}, 9.59 \mathrm{KN}$ and $11.51 \mathrm{KN}$ obtained from $0 \%, 2 \%, 4 \%$, $6 \%$, and $8 \%$ replacement with polypropylene is suitable for heavy, medium and light traffic in accordance with criteria for the marshal mix design method provided by the Asphalt Institute.

- The flow result from $0 \%$ to $8 \%$ with a values of $3.8 \mathrm{~mm}, 3.5 \mathrm{~mm}, 3.2 \mathrm{~mm}, 3.1 \mathrm{~mm}$, and $2.8 \mathrm{~mm}$ did not conformed with Asphalt Institute specification but satisfied to Nigeria general specification for road and bridge which stated that maximum of $4 \mathrm{~mm}$ to minimum of $2 \mathrm{~mm}$ is the acceptable range for wearing course in production of asphalt concrete.

- The air void values of $4.18 \%, 4.54 \%$ and $4.69 \%$ obtained from $0 \%, 2 \%$, and $4 \%$ respectively are within Asphalt institute criteria while 5.36\%, 5.76\% obtained from $6 \%$ and $8 \%$ did not satisfied the Asphalt institute specification.

- Other marshal properties such as void in mineral aggregate and void filled with bitumen satisfied the Nigeria general specification for road and bridges

- The study concluded disclosed that powdered polypropylene can be approved for use as replacement for bitumen in asphalt concrete.

- These results suggest that the replacement of powdered polypropylene could enhance the performance of asphalt concrete, decrease the cost road construction, and also reduced large volume of plastic in our environment.

\section{REFERENCES}

[1] Abu, A.M., Utilizing Reclaimed asphalt pavement, International Journal of Thermal and Environment Engineering, vol. 12, no. 1, 2016, p. 61-66.

[2] https://www.plasticseurope.org/application/files/5715/1717/4180/Plastics_the_facts_2017_FINAL_for_ website_one_page.pdf (15.08.2021).

[3] Kaza, L.S., Yao, P., Bhada-Tata, F., Van W., What a waste 2.0 a global snapshot of solid waste management to 2050, the World Bank, Ed. Urban Development, 2018.

[4] Uwaegbulam, C. B., Nwannekanma, V., Gbonegun, E., Producers responsibility and plastic pollution crisis, Environment, the Guardian Nigeria News, 2018.

[5] Hopewell, J.R., Dvorak, D., Kosior, E., Plastics recycling challenges and opportunities, Philosophic Transactions of the Royal Society, vol. 364, 2009, p. 2115, no. 21226.

[6] Huang, Y., Bird, R.N., Heidrich, O., A review of the use of recycled solid waste materials in asphalt pavements, Resources, Conservation and Recycling, vol. 52, no. 1, 2007, p. 58- 73.

[7] Kalantar, Z.N., Karim, M.R., Mahrez, A., A review of using waste and virgin polymer in pavement, Construction and Building Material, vol. 33, no. 2, 2012, p. 55-62.

[8] Vasudevan, R., Velkennedy, R., Ramaling, A., Chandra, S., Sundarakannan, R., Utilization of waste polymers for flexible pavement and easy disposal of waste polymers, International Journal of Pavement Resource Technology, vol. 3, no. 1, 2012, p. 34-42. 
[9] Khursheed, T., Singh, B.K., Road construction from solid waste in Jaipur, International Journal for Technological Research in Engineering, vol. 4, no. 9, 2017, p. 11-17.

[10] Bale, A.S., Potential reuse of plastic waste in road construction, International Journal of Advances in Engineering and Technology, vol. 2, no. 2, 2012, p. 233-236.

[11] Bhoot, K., Malviya, K., Prajapate, T.K., Potential reuse of plastic waste in road construction, International Journal of Scientific Research in Engineering, vol. 1, no. 9, 2012, p. 1-5.

[12] Manju, R.S., Sathya, S., Sheema, K., Use of plastic waste in bituminous pavement, International Journal of Chemical Technology Resource, vol. 10, no. 8, 2017, p. 804-811.

[13] Behl, A., Jain, P., Sharma, G., Study on waste polyvinyl chloride modified bitumen for paving applications, ARRB Conference, 25th, 2012, Perth, Western Australia, Australia.

[14] Sojobi, A.O., Nwobodo, S.E., Aladegboye, O.J., Recycling of polyethylene terephthalate (PET) plastic bottle wastes in bituminous asphaltic concrete, Cogent Engineering, vol. 3, no. 1, 2016, p. 113-140.

[15] Ahmad, M.A., Investigation the effects of adding waste plastic on asphalt mix performance, ARPN Journal of Engineering and Applied Sciences, vol. 12, no. 5, 2019, p. 4351-4356.

[16] Akinpelu, M., Bamidele, I.O.D., Oladipupo, O., Olufemi, A., Adedeji, Q., Effect of polythene modified bitumen on properties of hot mix asphalt, ARPN Journal of Engineering and Applied Sciences, vol. 8, no. 4, 2013, p. 290-295.

[17] Milad, A., Ahmed, S., Ali, A., Mohammed, B., Zubair, A., Nuha, S., Salaheddin, A., Nur, I.Y., Utilization of waste-based geopolymer in asphalt pavement modification and construction, Sustainability, vol. 13, no. 3330, 2021, p. 2-21.

[18] Oyedepo, O.J., Utilization of industrial waste products in the production of asphalt concrete for road construction, Slovak Journal of Civil Engineering, vol. 27, no. 4, 2019, p. 11-17.

[19] FGN, Government of the Federal Republic of Nigeria, General Specifications (Roads and Bridges), vol. II, 1997.

[20] Asphalt Institute, Criteria for the Marshall Mixture Design Method, 1997.

[21] Mohammed, T.A., Fadhad, B.M., Awwaba, I.S., The use of polyethylene in hot asphalt mixture, American Journal of Applied Science, vol. 21, no. 1, p. 390-396.

[22] Awaeed, K.M., Fahad, B.M., Rasool, D.A., Utilization of waste plastic water bottle as modifier for asphalt mixture properties, Journal of Engineering and Development, vol. 20, no. 2, 2015, p. 89-108.

[23] Aliyu, A., Usman, J., Kaura, M., Ashiru, E., Kingsley, I., Polyethylene from water sachet as a modifier in hot asphalt mixture, Department of Civil Engineering, Ahmadu Bello University, Zaria, Nigeria, 2015.

[24] Ahmadinia, E.M., Mohamed, R., Karim, B., Mahrez, A., Ebrahim, A., Performance evaluation of utilization of waste polyethylene terephthalate (PET) in stone mastic, Journal of Asphalt Construction and Building Material, vol. 1, no. 4, 2012, p. 984-989. 